\section{A CASE OF ANGIOMA OF THE ORO-PHARYNX.}

BY

W. SANDERSON, M.B., Сн.B., LIVERPOOL.

Axiroms is a disease not often found in the oro-pharynx. The first case of the kind recorded was by Wolfenden in the British Medical Journal, 1887, and the condition was described by him as being probably quite unique. In his case the growth involved the right half of the oropharynx and extended downwards to the level of the base of the tongue and upwards to a little above the level of the soft palate. A few cases of much smaller growth have been recorded since by McBride, Woods, Lichtwitz, and Laurens, but the greater portion of the tumour in these instances was located in adjacent parts-namely, the soft palate, faucial pillars, tonsils, and tongue.

The following case may therefore be of interest, not because of the symptoms or the treatment, which were practically nil, but on account of the rarity of the position of the growth, its extent, though localized to one particular area, and its appearances :

A spare, rather pale girl, aged 10, was brought by her mother on account of slight cough, which had been noticed off and on for about two years. A sister had been operated on some time previously for adenoids, and the mother thousht that the cough in the present case might be due to the same cause. The ex pectoration had been on one or two occasions slightly tinged wectoration blood. The patient herself felt quite well, had no diswith blood. The patient herself felt quite well, had no discomfort or difficulty in swallowing, and breathed with the mouth closed. On inspection a diffuse bluish-red growth was seen involving the pharyngeal wall in its posterior and latera aspects, extending on each side as far as the posterior fancial pillars. Posterior rhinoscopy showed that it ceased by a horizontal margin just above the level of the soft palate. There were no adenoids. The growth, though continuous, stood out in three verical ridges, which became pillar-like if the patien gagged-one central on the posterior wall and one on each lateral wall. On tracing these downwards with the laryngoscope, the central ridge was seen to terminate in a rounded bulbous extremity, which frequently came in contact with the tip of the extremity, which frequently came in contact with the tip of the epiglottis; the lateral masses reached to the same level and presented the same appearance as the central one. There was no pulsation. The general tint was dark red, interspersed with bluish streaks; the surface was finely irregular, and the whole area of the right posterior faucial pillar was also affected. The area of the right posterior faucial pillar was
growth on palpation was firm but not hard.

This, then, is the history and description of the case and one finds the latter to differ somewhat from that given in textbooks and recorded cases. In these the tumour is said to occur as a soft, purple, nodular growth of large varicose and tortuous veins, probably originating in Cruveilhier's plexus, and covered with intact mucous membrane.

In the case I have described there were no large vessels visible, and the mucous membrane itself was affected with the disease. Kyle, in his description of angioma of the upper air passages, states that the colour varies, depending upon the size of the tumour and its association with vein, with an artery, or with both. If connected with an arter:y it is usually light red and pulsates; if with a vein the colour is darker, bluish-red, and pulsation is slight or absent; if with both artery and vein-and this is said to be the most frequent-it is dark red. From the clinical aspect one would place the above case in the venocapillary group, and this was confirmed by microscopic examination of a portion removed by punch forceps from the right half of the growth.

A marked feature of naevi in the pharynx, and one which to a great extent influences the treatment of the condition, is the absence of symptoms. The majority of cases are accidentally discovered, and this may somewhat account for the fact that comparatively few cases have been recorded. Similar growths, on the other hand, occurring in the nose and larynx often bring the sufferers speedily for advice on account of obstruction in the nasa passages, epistaxis, muco-purulent discharge, interference with phonation, and respiratory troubles. Dr. Paul Lauren. described a case in 1907 of angioma of the pharynx and relum palati that he had cured after fifteen sittings by monopolar electrolysis, but, where pharyngeal naevi and those in adjacent parts are large and cause, little inconrenience, the general opinion at present is that it is better to leave them alone, and to instruct the patient to avoid food likely to abrade or tear the diseased part.

\section{EARLY EXCISION OF BOILS. \\ BY \\ J. CROPPER, M.A., M.D.CANTAB., CHEPSTOW, MON.}

THE results obtained by the method described below hare been so encouraging during the last few years that I make no apology for publishing it.

A boil or furuncle may be described as a localized necrosis of the dermis resulting from intense inflammation due to staphylococcic infection. The efforts of Nature to throw the dead part off by ulceration-in other words, the separation of the slough-complete the process.

Since most, if not all, surgical operations are a frank imitation of natural processes, and are merely designed to accelerate these, it occurred to me that in the case of a boil, when once the inflammatory process was under way, all that one could do was to remove the central area of skin, which would sooner or later undergo necrosis, and thus forestall Nature, and that this would at once relieve stasis. The treatment by a crucial incision does not achieve this end in a satisfactory manner. I omit here any account of methods of treatment by pure carbolic acid or epilation, because I have rarely found them of any use beyond the first or second day. Afterwards there is a good deal of irritation and more drastic methods are needed. I tried the method first on myself on two occasions with most gratifying results. All pain was at once at an end and the scar was trifling.

An ethyl chloride spray, a sharp cataract (Graefe's) knife, and a pair of dissecting forceps are all that are required. The skin over and around the boil is well frozen. This renders it firm and easily cut, which is a great point. With the cataract knife held perpendicularly to the skin surface, a circular disc of the whole skin of the size of a wheat seed or small pea is removed by sawing movements. Where there is much inflammation the diameter of the piece removed may be $t$ in., but it need never be larger if tackled early. The pain caused by this procedure is really trifling, even when carried out on the tender inner part of the leg, and the bleeding is insignificant, and should be encouraged by warm bathing. The subsequent treatment by any form of antiseptic dressing seems to be of quite minor importance. It can be fixed by strapping. There is usually a little suppuration, but, from the moment of the operation, the throbbing and intense soreness are at an end.

I have personal experience of the relief to be obtained, and I find that somewhat hysterical girls will come back for treatment to be repeated, even on the face.

Not the least of the advantages is that the resulting scar, which is minute, is far less than the unsightly lumps so often left after ordinary treatment by poulticing, etc. Moreover, the danger of a secondary infection by the pus is reduced to a minimum. Where this method has been carried out properly complete success has resulted. and even where it has been badly done there has been considerable relief in all cases. The following are the words of one of my patients treated on the sixth day:

Before the operation.I had a great deal of pain and throbbing so that I could hardly walk at all but had to lie down most of the time. The swelling of the leg became very painful on standing. I was somewhat apprehensive that the operatiou might be painful, but as a matter of fact I hardly felt the knife at all when the skin was frozen. As soon as it was over. I experienced intense relief instantly, and suffered no over: pain but only some slight soreness from the healing of the wound.

The deep purple congestion of the leg disappeared almost at once, and ten days later, after some suppuration, the wound was nearly closed.

AT the recent examination for sanitary inspectors under the Public Health (London) Act, 1891, held by the Sanitary Inspectors Examination Board, fourteen candidates were successful, of whom six were women. Two candidates were also successiul in the examination for the special certificate for inspectors of meat and other foods held in conjunction with the above examination. 